\title{
COMUNICAÇÃO CIENTÍFICA \\ Método simplificado para obtenção de secções finas de osso mineralizado
}

\section{A simplified method to obtain thin sections of mineralized bone}

\author{
Valéria Silva Braz, * Marcelo Abidu-Figueiredo**
}

\begin{abstract}
Resumo
O presente trabalho propõe uma técnica simples para o processamento de secções finas de tecido ósseo mineralizado com baixo custo. Dez eqüinos foram analisados. De cada animal o terceiro metacarpo foi extraído e seccionado na diáfise. Cada fragmento obtido foi processado por abrasão mecânica utilizando-se uma seqüência de lixas até a obtenção da espessura desejada. Os resultados obtidos criam uma nova perspectiva quanto a aplicabilidade de tal técnica em microrradiografias e análises histomorfométricas de tecidos biomineralizados.
\end{abstract}

Palavras-chave. secções finas, osso mineralizado.

\begin{abstract}
The present study introduces a simplified technique to prepare thin ground sections ( $\leq 10 \mathrm{~mm}$ ) of mineralized bone with low cost. Ten horses were analyzed. Of each one, the third metacarpus were extracted and processed by sequential mechanical abrasion. The precise results showed that the extra-thin sections were suitable for microradiographic and histomorphometric studies.
\end{abstract}

Keywords: thin sections, mineralized bone.

Observando, macroscopicamente, as estruturas internas do osso, podemos identificar a existência de dois componentes estruturais: o osso cortical (ou compacto), que constitui aproximadamente $80 \%$ do esqueleto maduro, presente preferencialmente na periferia dos ossos; e o osso esponjoso (ou trabecular) que compõe $20 \%$ do esqueleto e encontrado nas epífises dos ossos longos e no interior dos demais ossos (Nordin e Frankel 1980; Buckwalter et al., 1995). Embora, nos dois tipos de ossos, a composição química seja a mesma, diferenças na distribuição, na arquitetura e na densidade são responsáveis por especializações em suas propriedades mecânicas (Aaron et al., 1987).

O estudo dos tecidos mineralizados (ossos e dentes), com os mais variados enfoques, foi intensificado a partir da década de 1960 em função do aprimoramento das técnicas de preparo de lâminas histológicas por abrasão e através da microtomia com navalha de diamante (Frost, 1958; Fremlin et al., 1961; Osborne, 1967).

No entanto, a utilização de micrótomos especiais no processamento de tecidos que apresentam uma matriz extracelular mineralizada, porém sem empregar descalcifição, nem sempre se faz possivel, tendo-se em vista o alto custo de tais aparelhos (Osborne, 1967; Fremlin et al., 1961). Por outro lado, a técnica mais clássica para obtenção de secções extrafinas de tecidos mineralizados, incluídos ou não, em resinas do tipo epóxi, a partir da abrasão mecânica manual, em geral, é muito laboriosa e oferece resultados aquém dos almejados, com espessuras superiores a 50 $\mu \mathrm{m}$ (Frost, 1958).

O presente trabalho apresenta uma nova alternativa para o processamento histológico de tecidos mineralizados, que permite a obtenção de secções finas $(\leq 10 \mathrm{~mm})$ a baixo custo.

Foram utilizados 10 eqüinos adultos de ambos os sexos, mestiços, provenientes de óbitos ocorridos no Hospital Veterinário e doados após necropsia, para a Área de Anatomia Animal. De cada animal foram desarticulados os membros torácicos, descarnados e macerados para obtenção dos ossos conforme a técnica anatômica (Rodrigues, 1998).

O terceiro metacarpo direito de cada animal foi seccionado transversalmente no nível da diáfise, obtendo-se fragmentos aproximadamente arredondados com cerca de $2 \mathrm{~cm}$ de espessura.

Primeiramente, uma das faces de cada uma das amostras foi polida, em todas as direções, cơm a lixa de número 240 , até se atingir $2 / 3$ de sua espessura original. Posteriormente, procedeu-se outro polimento, menos abrasivo, agora com a 
lixa de número 500 , até que a metade da amostra fosse atingida. Todo o procedimento abrasivo ocorreu na presença de água corrente para se evitar maiores danos às amostras. Após o procedimento acima descrito, as amostras foram lavadas com água destilada e secadas em uma estufa a $60^{\circ} \mathrm{C}$ por 10 minutos.

As amostras após o procedimento abrasivo foram, então, fixadas em lâminas de vidro com a aplicação de pequena quantidade da resina cianoacrílica SuperBonder Loctite ${ }^{\circledR}$ na superfície previamente polida. O tempo médio de secagem da resina, à temperatura ambiente $\left(-25^{\circ} \mathrm{C}\right)$, foi de duas horas.

$\mathrm{Na}$ outra face da lâmina que não recebeu o fragmento ósseo, fixou-se um par de ventosas de borracha com $2 \mathrm{~cm}$ de diâmetro, onde se segura a lâmina com apoio ideal possibilitando uma igual distribuição da pressão exercida sobre a amostra. Com isso, na face da amostra que ainda não sofreu polimento, novo procedimento abrasivo é realizado de forma idêntica ao descrito acima.
Quando a amostra começou a apresentar um aspecto translúcido $(\sim 50 \mu \mathrm{m})$, o polimento foi continuado com a utilização da lixa de $13 \mu \mathrm{m}$ que elimina a maior parte dos arranhões acarretados pela utilização das lixas anteriores, até que se atinja a transparência $(\leq 10 \mathrm{~mm})$.

As lâminas foram montadas com lamínulas e bálsamo do Canadá.

As amostras obtidas foram analisadas por microscopia óptica de campo claro e de polarização, através de um microscópio Axioplan Zeiss, revelando resultados muito finos e bem detaIhados da distribuição dos osteonios (Figura 1).

A espessura das secções também foi aferida por microscopia óptica.

A qualidade das imagens cria, também, uma nova perspectiva quanto à aplicabilidade de tal técnica em microrradiografias e análises histomorfométricas de tecidos biomineralizados.

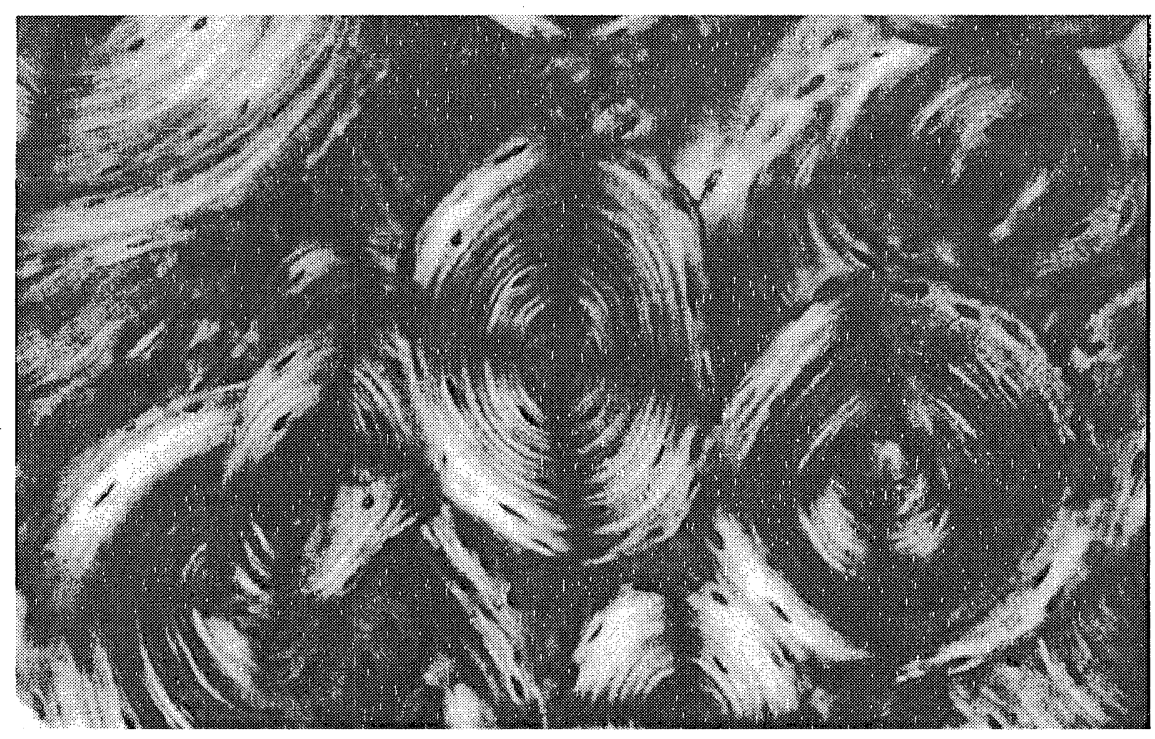

Figura 1: Fotomicrografia de secção transversal de fragmento de metacarpo de eqüino sob luz polarizada. $(200 x)$ Os = Osteôneo $\mathrm{CH}=$ Canal de Havers

\section{Referências}

AARON, J.E.; MAKINS, N.B.; SAGREYA, K. The Microanatomy of Trabecular bone loss in normal aging men and woman. Clin. Orthop., v. 215, p. 260-271,1987.

BUCKWALTER, J.A.; GLINCHER, M.J.; COOPER, R.R., RECKER, R. Bone Biology. Par I-Structure, blood supply, matrix and mineralization. J. Bone Joint. Surg. [Am.], v. 77, n. 8, p. 1256-1289, 1995.

FROST, H.M. Preparation of thin undecalcified bone sections by rapid manual method. Stain Technol., v. 33, p. 273-276, 1958.
FREMLIN, J. H.; MATHIESON, J.; HARDWICK, J. L. Preparation of thin sections of dental enamel. Arch. Oral Biol., v. 5, p. 55-60, 1961.

NORDIN, M.; FRANKEL,V.H. Biomechanics of whole bones and bone tissue. In: NORDIN, M., FRANKEL,V.H. Basic biomechanics of Skeletal System. Philadelphia: Lea \& Feibiger, p. 15-60, 1980.

RODRIGUES, H. Técnicas Anatômicas. Vitória, 1988.

OSBORNE, J.W. Evaluation of previous assessments of prism directions in human enamel. J. Dental Res., v. 47, n. 2, p: 217-22, 1968. 